\title{
Prevalence and Risk Factors of Chronic Obstructive Pulmonary Disease in Kashi Region, Northwestern China
}

This article was published in the following Dove Press journal: International Journal of Chronic Obstructive Pulmonary Disease

Li Li, '* Xuemei Zhong, ${ }^{1} *$ Aifang Zheng,' Chen JianKun, 2,3 Ayiguzali A Budukadeer,' Paierda Aini, ' Maimaitiaili Tuerxun,' Mukeremu Yasen,' Tao Ma,' Jie Ren,' Rukeyamu Semaiti, ' Chengxin Xie, ' Feifei Li,' Mireban Rexiati,' Lifeng Tang,' Gulanbaier Abudurexiti,' Dayong Zheng,' Ji-Qiang $\mathrm{Li}^{\mathrm{I}}{ }^{-3}$

'Department of Respiratory and Critical Care Medicine, The First People's Hospital of Kashi Prefecture, Kashi, Xinjiang, People's Republic of China; ${ }^{2}$ The Second Clinical College, Guangzhou University of Chinese Medicine, Guangzhou, People's Republic of China; ${ }^{3}$ The Third Comprehensive Department, The Second Affiliated Hospital, Guangzhou University of Chinese Medicine (Guangdong Provincial Hospital of Chinese Medicine), Guangzhou, People's Republic of China

*These authors contributed equally to this work

Correspondence: Dayong Zheng Department of Respiratory and Critical Care Medicine, The First People's Hospital of Kashi Prefecture, 120 Yingbin Road, Kashi City, Xinjiang, 844000, People's Republic of China

Tel + I3570029702

Email zdy525679@163.com

Ji-Qiang Li

The Second Clinical College, Guangzhou University of Chinese Medicine, 232

Waihuan East Road, Guangzhou

University City, Panyu District of

Guangzhou, Guangzhou, 510120, People's

Republic of China

$\mathrm{Tel}+13527675982$

Email Ljq525679@I26.com
Objective: To investigate the prevalence and the risk factors of COPD in the Uyghur population in the Kashi region.

Methods: From August 2018 to March 2019, we recruited participants of Uyghur ethnicity and aged $\geq 40$ years old from the Kashi region using a combined cluster sampling and random sampling method. We collected potential risk factors using questionnaire, and conduced lung function using a portable pulmonary function instrument.

Results: A total of 2963 participants were included in this analysis, of whom 1268 were males and 1695 were females. There were 504 participants with COPD, generating a prevalence of $17.01 \%$. With the increase of age, the prevalence of COPD in different genders increased significantly. The results of different regions were $\chi^{2}=627.89, p<0.01$, indicating significant differences in the prevalence in different regions. Among them, based on the existing survey data, it is speculated that Shache county has the highest crude prevalence, but the sample size needs to be further expanded. The participants with high age, smoking, lower BMI, high waist circumference, systolic blood pressure, fried cooking and barbecue share more COPD than those who partake of fruits and vegetables in this study. Conclusion: The prevalence of COPD among the Uyghur population in the Kashi region is higher than the national rural average. Among them, high age, smoking, low BMI, high waist circumference, high systolic blood pressure, cooking methods that may be stir-fried and deep-fried barbecue are risk factors for COPD, and vegetable and fruit intake may be a protective factor for COPD.

Keywords: Uyghur population, chronic obstructive pulmonary disease, prevalence, risk factors, epidemiology study

\section{Background}

Chronic obstructive pulmonary disease (COPD) is a chronic respiratory disease characterized by continuous airflow limitation. The prevalence of COPD is on the rise year by year, bringing a heavy economic burden to society. COPD is emerging as one of the leading causes of disability and death, and is projected to be the seventh largest disease burden worldwide by 2030 .

Reported COPD prevalence varied between $1.20 \%$ and $8.87 \%$ in different provinces/cities across China. The disease was more prevalent in rural areas $(7.62 \%)$ than in urban areas $(6.09 \%){ }^{1}$ Although similar epidemiological surveys have been carried out in China, the epidemic situation in some areas (especially in remote areas) is still unclear. The risk factors of COPD are still unclear and need to be further explored. 
The Kashi region of China is adjacent to the Taklimakan desert in the east, Kunlun mountain in the south, and Pamir plateau in the west. Due to less precipitation and severer water shortage and desertification, air pollution in this area is more critical than in other regions in China. Most of the epidemiological investigation population of COPD in China is of the Han population in urban areas, but the epidemiological investigation of COPD in the rural population of the Uyghur in the Kashi region has not been reported. The risk factors of COPD in the Kashi area are not clear and need to be further explored because of the common influence of different regions, races, climates and living habits, there are some differences in COPD related epidemiological investigations and exposure of risk factors. Through epidemiological investigation, we aimed to understand the incidence and risk factors of COPD in the Kashi area which can provide more targeted measures for the prevention and treatment of COPD.

\section{Methods}

\section{Study Design and Participants}

This survey was conducted from July 1, 2018 to April 30, 2019. We employed a multistage stratified cluster sampling procedure to collect study participants. A total of 3391 people were initially invited, of whom 428 were excluded due to incomplete lung function data and/or incomplete questionnaire data. Finally, 2963 participants were included in the current study. This study was approved by the ethics committee of the first people's hospital of Kashi and all subjects signed informed consent. All subjects were informed and informed consent was signed. We confirm this study was conducted in accordance with the Declaration of Helsinki.

\section{Data on Potential Risk Factor}

The questionnaire was formulated with reference to the COPD burden research project of the World Health Organization, ${ }^{2}$ and the contents of the questionnaire were supplemented in combination with the diet and living habits of the Uyghur population in the Kashi region. The contents of the questionnaire include: (1) Basic information (age, gender, physical exercise, kitchen ventilation, cooking style, personal cooking, smoking, vegetable and fruit intake, BMI, waist circumference, hip circumference, systolic blood pressure.); (2) Living and cooking habits (including cooking, main fuels, cooking methods, kitchen ventilation, kitchen ventilation facilities, heating methods in winter and heating fuel, raising pigeons, etc.); (3) Smoking history (including smoking, number of cigarettes, smoking time, smoking cessation, passive smoking, etc.); (4) Clinical features of COPD (chest pain, cough, dyspnea, edema of both lower limbs, cough, expectoration and shortness of breath due to seasonal change and cooling of the weather, and symptoms of cough and asthma due to irritating smell. Whether there is a cough and expectoration for 2 consecutive years, 3 months a year or more in total, with mucus expectoration, and recent respiratory diseases such as cold, tracheitis and pneumonia); (5) Family history of COPD-like illness (one of the parents, siblings with chronic bronchitis, COPD or asthma was defined as having a family history of respiratory diseases); (6) Cognition and treatment of COPD in patients with different severities of COPD.

After the unified training, the respiratory specialist conducted a comprehensive inquiry and physical examination (including height, weight, waist circumference, hip circumference, measure blood pressure, etc.) according to the unified questionnaire, and completed the questionnaire.

\section{Measures}

Lung function and the professional and technical personnel, in accordance with the Chinese medical association respiratory neurology. The inclusion criteria of patients met the diagnostic criteria of COPD of the 2017 edition of the global obstructive pulmonary disease (GOLD), ${ }^{3}$ that is the one-second rate (FEV1/FVC) is less than $70 \%$ after 30 minutes of inhaling bronchodilatation drugs, and other cardiopulmonary diseases that can affect lung function were excluded by history, chest radiograph, and electrocardiogram.

\section{Statistical Analysis}

The questionnaire data were recorded independently by two people using Epi-data software, and checked, verified and corrected. SPSS 18.0 software was used and statistical analysis was performed. The measurement data were expressed as $x \pm \mathrm{s}$, and $t$-test was used for comparison between the two groups. The count data were expressed by the number of cases and percentage. The statistical significance of the difference was assessed by the $\chi^{2}$ test. Logistic regression analysis was performed to assess the 
relationships of potential risk factors with COPD. The $P<0.05$ was considered as statistically significant.

\section{Result}

\section{Basic Situation}

A total of 2963 people were invited, 1268 males and 1695 females were included in the analysis. Mean (SD) age of the participants was 55.4( \pm 11.1$)$ years. There were 504 participants with COPD, generating a prevalence of $17.01 \%$.

\section{Prevalence of COPD in Different Ages and Gender Groups}

The prevalence of COPD increased with age in both males and females. For example, in males the COPD prevalence increase from $4.2 \%$ in participants aged 24-40 years to $32.2 \%$ in participants aged over 70 years. Similar trends were observed in females (Table 1).

\section{Prevalence of COPD in Different Geographical Regions}

We observed that the prevalence of COPD significantly differed by geographical regions $(\chi 2=627.89, \mathrm{P}<0.01)$. The highest prevalence was observed in Shache county, followed by Baya wat, and Yue pu hu county, and the lowest was observed in village 5, Yue pu hu county (Table 2).

\section{Potential Risk Factors of COPD Single Factor Analysis}

In single-variate logistic analysis, we observed that old age, gender, physical activity, kitchen ventilation, cooking style, personal cooking, smoking, vegetable and fruit intake, BMI, waist circumference, hip circumference, and systolic blood pressure were significantly associated with COPD. (Table 3)

\section{Multi-Factor Analysis}

In multi-variate analysis, high age, smoking, low BMI, high waist circumference, high systolic blood pressure and fried and barbecue cooking methods were significantly associated with an increased risk of COPD, while intake of vegetables and fruits were associated with a decreased risk of COPD. (Table 4)

\section{Family History of COPD Patients}

Parents were surveyed as well as if one of their siblings had chronic bronchitis, chronic obstructive pulmonary disease, and asthma. Either was defined as having a family history of respiratory disease. Uni-factor logistic regression analysis showed that the OR value of respiratory disease history was $1.13(0.75,1.66)$, and $P>0.05$, showing no statistical significance (Table 5).

\section{The Cognition and Treatment Status of Patients with COPD of Different Severity to COPD Disease}

A total of 504 patients with COPD were diagnosed in this epidemiological survey, and COPD classification criteria were determined as level 4 , among whom most investigators were mild and moderate patients with COPD ( $\mathrm{n}=$ 404 ), accounting for $80.2 \%$. The number of severe patients was 82 , accounting for $16.3 \%$. The critical degree of patients was 18 , accounting for $3.5 \%$. Chi-square test and Fisher's exact test found that cough, expectoration and shortness of breath were significantly correlated with COPD severity (Table 6).

\section{Clinical Features of COPD}

Based on a variety of different clinical symptoms for a chisquare test and single factor logistic regression it was

Table I Prevalence Rates of COPD in Different Age Groups

\begin{tabular}{|l|c|c|c|c|c|c|c|c|c|}
\hline \multirow{2}{*}{$\begin{array}{l}\text { Age Group } \\
\text { (Years) }\end{array}$} & \multicolumn{4}{|c|}{ Male } & \multicolumn{3}{c|}{ Female } & \multicolumn{3}{c|}{ Total } \\
\cline { 2 - 11 } & Number & COPD & Prevalence (\%) & Number & COPD & Prevalence (\%) & Number & COPD & Prevalence (\%) \\
\hline $24 \sim 40$ & 24 & 1 & 4.17 & 45 & 4 & 8.89 & 69 & 5 & 7.25 \\
\hline $40 \sim$ & 359 & 51 & 14.21 & 594 & 66 & 11.11 & 953 & 117 & 12.28 \\
\hline $50 \sim$ & 367 & 60 & 16.35 & 547 & 68 & 12.43 & 914 & 128 & 14.00 \\
\hline $60 \sim$ & 304 & 75 & 24.67 & 327 & 56 & 17.13 & 631 & 131 & 20.76 \\
\hline $70 \sim$ & 214 & 69 & 32.24 & 182 & 54 & 29.67 & 396 & 123 & 31.06 \\
\hline Total & 1268 & 256 & 20.19 & 1695 & 248 & 14.63 & 2963 & 504 & 17.01 \\
\hline
\end{tabular}


Table 2 Prevalence of COPD in Different Regions and Age, Adjusted Prevalence by Gender and Their 95\% Confidence Intervals

\begin{tabular}{|c|c|c|c|c|c|c|c|}
\hline Region & $\begin{array}{l}\text { Number } \\
\text { of Survey }\end{array}$ & $\begin{array}{l}\text { Case of } \\
\text { COPD } \\
(\%)\end{array}$ & $\begin{array}{c}\text { 95\% Lower } \\
\text { Limit (\%) }\end{array}$ & $\begin{array}{c}95 \% \text { Upper } \\
\text { Limit (\%) }\end{array}$ & $\begin{array}{c}\text { Age and Gender } \\
\text { Standardized Prevalence } \\
(\%)\end{array}$ & $\begin{array}{c}\text { 95\% Lower } \\
\text { Limit (\%) }\end{array}$ & $\begin{array}{c}\text { 95\% Upper } \\
\text { Limit (\%) }\end{array}$ \\
\hline Bayawat, Yue pu hu & 283 & $64(22.6)$ & 19.17 & 26.56 & 21.50 & 17.93 & 25.07 \\
\hline Bashkeram, Kashi & 236 & $18(7.6)$ & 4.10 & 11.15 & 6.19 & 3.22 & 9.16 \\
\hline Eshman, Yue pu hu & 73 & $3(4.1)$ & - & 8.76 & 4.13 & - & 9.24 \\
\hline Pahtirek, Kashi & 65 & $12(18.5)$ & 8.02 & 28.91 & 21.94 & 7.66 & 36.21 \\
\hline Village 4, Kashgar & 156 & $33(21.2)$ & 13.94 & 28.37 & 18.94 & 12.14 & 25.75 \\
\hline Village 9, Kashi & 137 & $15(11.0)$ & 5.41 & 16.49 & 10.62 & 4.96 & 16.29 \\
\hline Village I5, Kashi & 150 & $21(14.0)$ & 8.01 & 19.99 & 18.62 & 8.68 & 28.55 \\
\hline Villages I0, Kashi & 88 & 14 (I5.9) & 7.58 & 24.24 & 14.65 & 6.27 & 23.02 \\
\hline Villages I2, Kashi & 245 & $35(14.3)$ & 9.55 & 19.02 & 15.22 & 10.05 & 20.39 \\
\hline Village 20, Kashi & 275 & $37(13.5)$ & 9.12 & 17.79 & 13.74 & 9.27 & 18.21 \\
\hline Village 18 , Kashi & 139 & $14(10.1)$ & 4.80 & 15.35 & 10.33 & 4.74 & $15.9 \mid$ \\
\hline Village 17, Kashi & 145 & $16(11.0)$ & 5.63 & 16.44 & 12.32 & 5.91 & 18.72 \\
\hline Village 19, Kashi & 263 & $16(6.1)$ & 3.10 & 9.07 & 6.49 & 3.14 & 9.84 \\
\hline Village 13, Kashi & 176 & $14(8.0)$ & 3.79 & 12.12 & 9.07 & 4.24 & 13.90 \\
\hline Village 5 , Yue pu hu & 64 & I (I.6) & - & 4.63 & 1.37 & - & 4.07 \\
\hline Shache county & 468 & $108(23.1)$ & 65.88 & - & 100.00 & 62.68 & - \\
\hline Total & 2963 & $504(17.0)$ & 3.23 & 30.79 & - & - & - \\
\hline
\end{tabular}

found that in addition to the chest pain, cough, dyspnea, double leg edema, cough due to seasonal changes as the weather gets cold, coughing up phlegm, shortness of breath, and smell excitant odor cough, asthma symptoms, having for 2 years in a row, each year more than 3 months or cumulatively for 3 months of coughing and expectoration, coughing up phlegm, recently had a cold, bronchitis, pneumonia and other respiratory disease factors are associated with a significant risk of COPD, and the OR values were greater than 2 , prompting the clinical characteristics of patients with COPD is that there is no risk of the clinical symptoms more than 1 time (Table 7).

\section{Discussion}

With the development of medical technology, people know in advance if they have some early period of disease, when the body appears to have some unusual characteristics. Through proper testing technology, and taking the appropriate treatment, we can significantly improve the cure rate of the disease and promote the patient's quality of life by reducing the risk of death. This kind of early disease prevention screening adopted by most research is about the epidemiological investigation of COPD, through early screening of the disease for the early prevention of the disease, we can reduce the prevalence and mortality. In recent years, researchers in various regions of the world have carried out epidemiological investigations of COPD on different scales. As of 2010, the total prevalence of COPD worldwide was $11.7 \%$, with an estimated 384 million people suffering from COPD globally. ${ }^{4}$ Due to the differences in the survey methods, diagnostic criteria and analytical methods adopted in each epidemiological survey, the prevalence data of COPD vary greatly. The prevalence of COPD increased year by year in all regions of the world, whether urban or rural. The prevalence rate of COPD increased rapidly in America, from $13.3 \%$ in 1990 to $15.2 \%$ in 2010 . The prevalence of COPD in Africa increased more slowly, from $9.8 \%$ in 
Table 3 Basic Characteristics and Single Factor Analysis of the Research Population

\begin{tabular}{|c|c|c|c|c|}
\hline \multirow[t]{2}{*}{ The Crowd Characteristics } & \multirow{2}{*}{$\begin{array}{l}\text { COPD } \\
(n=504)\end{array}$} & \multicolumn{2}{|l|}{ Non-COPD } & \multirow{2}{*}{$\begin{array}{l}\text { Total } \\
(n=2963)\end{array}$} \\
\hline & & $(n=2459)$ & p-value & \\
\hline Age $(n, \%) b$ & & & $<0.001$ & \\
\hline $24 \sim 40$ & $5(1 \%)$ & $64(3 \%)$ & & $69(2 \%)$ \\
\hline $40 \sim 50$ & 117 (23\%) & $836(34 \%)$ & & $953(32 \%)$ \\
\hline $50 \sim 60$ & $128(25 \%)$ & $786(32 \%)$ & & $914(31 \%)$ \\
\hline $60 \sim 70$ & $|3|(26 \%)$ & $500(20 \%)$ & & $631(21 \%)$ \\
\hline$\geq 70$ & $123(24 \%)$ & $273(11 \%)$ & & $396(13 \%)$ \\
\hline Gender (n,\%) & & & $<0.001$ & \\
\hline Male & $256(51 \%)$ & $1012(41 \%)$ & & $1268(43 \%)$ \\
\hline Female & $248(49 \%)$ & I 447 (59\%) & & $1695(57 \%)$ \\
\hline Physical exercise outside work (n,\%) & & & $<0.001$ & \\
\hline Yes & $174(35 \%)$ & $694(28 \%)$ & & $868(29 \%)$ \\
\hline No & $330(65 \%)$ & $1765(72 \%)$ & & 2095 (71\%) \\
\hline Professional $(\mathrm{n}, \%)$ & & & 0.166 & \\
\hline Farmer & $443(88 \%)$ & 2206 (90\%) & & 2649 (89\%) \\
\hline Other & $61(12 \%)$ & $243(10 \%)$ & & $304(10 \%)$ \\
\hline Education level $(n, \%)$ & & & 0.793 & \\
\hline Primary school culture or illiteracy & $395(78 \%)$ & 1943 (79\%) & & $2338(79 \%)$ \\
\hline Junior high school or above & $109(22 \%)$ & $516(21 \%)$ & & $625(21 \%)$ \\
\hline Kitchen ventilation $(\mathrm{n}, \%)$ & & & $<0.001$ & \\
\hline Good & $89(18 \%)$ & $335(14 \%)$ & & 424 (I4\%) \\
\hline General & $396(79 \%)$ & $2111(86 \%)$ & & 2507 (85\%) \\
\hline Bad & $19(4 \%)$ & $13(1 \%)$ & & $32(1 \%)$ \\
\hline Whether to use a range hood (yes, $n, \%$ ) & $10(2 \%)$ & $43(2 \%)$ & 0.858 & $53(2 \%)$ \\
\hline Cooking method $(n, \%)$ & & & 0.047 & \\
\hline Cook & 138 (27\%) & 787 (32\%) & & $925(31 \%)$ \\
\hline Stir-fried & $366(73 \%)$ & $1672(68 \%)$ & & $2038(69 \%)$ \\
\hline Cook for yourself $(n, \%)$ & & & $<0.001$ & \\
\hline Often & $174(35 \%)$ & 1127 (46\%) & & $|30|(44 \%)$ \\
\hline Once in a while & $130(26 \%)$ & $539(22 \%)$ & & $669(23 \%)$ \\
\hline No & $200(40 \%)$ & $793(32 \%)$ & & $993(34 \%)$ \\
\hline Winter heating mode $(n, \%)$ & & & 0.851 & \\
\hline Coal stove & $495(98 \%)$ & 2409 (98\%) & & 2904 (98\%) \\
\hline Other & $9(2 \%)$ & $50(2 \%)$ & & $59(2 \%)$ \\
\hline Smoking (yes, n,\%) & 116 (23\%) & $346(14 \%)$ & $<0.001$ & $462(16 \%)$ \\
\hline Drinking (yes, n,\%) & $24(5 \%)$ & $110(4 \%)$ & 0.868 & $134(5 \%)$ \\
\hline Daily intake of fruits and vegetables (yes, n,\%) & $442(88 \%)$ & $2236(91 \%)$ & 0.031 & $2678(90 \%)$ \\
\hline Whether to feed and touch pigeons (yes, n,\%) & $215(43 \%)$ & 965 (39\%) & 0.169 & $1180(40 \%)$ \\
\hline BMI, $\mathrm{kg} / \mathrm{m}^{2}($ mean $\pm \mathrm{SD})$ & $23.4 \pm 4.34$ & $25.2 \pm 4.3$ & $<0.001$ & \\
\hline Waist circumference, $\mathrm{cm}$ (mean $\pm \mathrm{SD})$ & $92.4 \pm 11.8$ & $95.5 \pm 11.3$ & $<0.001$ & \\
\hline Neck circumference, cm (mean \pm SD) & $36.6 \pm 3.7$ & $36.5 \pm 3.6$ & 0.514 & \\
\hline Hip circumference, cm (mean $\pm S D$ ) & $96.5 \pm 10.2$ & $100.6 \pm 10.6$ & $<0.001$ & \\
\hline Systolic, $\mathrm{mmHg}$ (mean $\pm \mathrm{SD})$ & $133.0 \pm 25.9$ & $129.0 \pm 23.5$ & 0.001 & \\
\hline Diastolic, $\mathrm{mmHg}($ mean $\pm \mathrm{SD})$ & $76.6 \pm 14.1$ & $76.1 \pm 13.4$ & 0.460 & \\
\hline
\end{tabular}


Table 4 Multivariate Logistic Regression Model of COPD

\begin{tabular}{|c|c|c|c|c|c|}
\hline Factors & Regression Coefficient & Standard Error & WALD & $\mathbf{P}$ & OR $(95 \% \mathrm{Cl})$ \\
\hline Constant term & -0.263 & 0.658 & -0.400 & 0.689 & 0.77 \\
\hline Age & 0.031 & 0.005 & 6.709 & $<0.001$ & $1.03(1.02,1.04)$ \\
\hline Gender & -0.133 & 0.12 & -1.106 & 0.269 & $0.88(0.69, \mathrm{I} . \mathrm{II})$ \\
\hline Physical activity outside work & 0.377 & 0.082 & 4.585 & $<0.001$ & $\mathrm{I} .46(\mathrm{I} .24, \mathrm{I} .7 \mathrm{I})$ \\
\hline Kitchen ventilation & 0.269 & 0.144 & 1.875 & 0.061 & I.3I $(0.98, \mid .73)$ \\
\hline Cooking methods & 0.204 & 0.116 & 1.754 & 0.079 & $1.23(0.98,1.54)$ \\
\hline Smoking & 0.582 & 0.147 & 3.972 & $<0.001$ & $1.79(1.34,2.38)$ \\
\hline Daily intake of fruits and vegetables & -0.361 & 0.167 & -2.163 & 0.031 & $0.70(0.51,0.97)$ \\
\hline BMI & -0.098 & 0.017 & -5.646 & $<0.001$ & $0.91(0.88,0.94)$ \\
\hline Waist circumference & 0.024 & 0.007 & 3.285 & 0.001 & $1.02(1.01,1.04)$ \\
\hline Hip circumference & -0.034 & 0.007 & -4.601 & $<0.001$ & $0.97(0.95,0.98)$ \\
\hline Systolic pressure & 0.005 & 0.002 & 2.388 & 0.017 & I.0I $(1.00,1.01)$ \\
\hline
\end{tabular}

Table 5 Univariate Logistic Regression Analysis of Family History of COPD

\begin{tabular}{|l|l|l|l|l|l|}
\hline $\begin{array}{l}\text { A Family } \\
\text { History of }\end{array}$ & COPD & Healthy & $\chi^{2}$ & P & OR (95\% CI) \\
\hline Yes & 472 & 2320 & & & \\
\hline No & 32 & 139 & 0.26 & 0.61 & I.I3 $(0.75, I .66)$ \\
\hline
\end{tabular}

1990 to $11.4 \%$ in 2010. The prevalence of COPD in Europe increased from $11.8 \%$ to $13.7 \%$.The prevalence of COPD in southeast Asia was 7.9\% in 1990 and $9.7 \%$ in $2010 .^{5}$ In 2002 in China there was also a COPD epidemiological investigation, led by Professor Zhong nan shan, in 7 provinces of China adults over the age of 40 underwent a COPD epidemiological investigation which found that the overall prevalence of COPD was $8.2 \%$, estimating that the number of cases of COPD is as high as 43 million in our country, the male prevalence rate was $12.4 \%$, the female prevalence was $5.1 \% .^{6}$ In 2007 , a national epidemiological survey showed that the prevalence of COPD among people over 40 years old in China was $8.2 \%$. The epidemiological survey of COPD was completed in 2013 by the Guang Zhou Graduate School of Medicine, which concluded that the incidence of COPD

Table 6 Analysis of Patients with Different Severity of COPD on the Cognition of COPD Disease, and the Status of Visit

\begin{tabular}{|c|c|c|c|c|c|}
\hline \multirow[t]{2}{*}{ Cognition, Medical Condition } & \multicolumn{4}{|c|}{ Classification of COPD } & \multirow[b]{2}{*}{$\mathbf{P}$} \\
\hline & $\begin{array}{c}\text { Mild } \\
(n=134)\end{array}$ & $\begin{array}{l}\text { Moderate } \\
(n=270)\end{array}$ & $\begin{array}{c}\text { Severe } \\
(n=82)\end{array}$ & $\begin{array}{c}\text { Severe Degree } \\
\quad(n=18)\end{array}$ & \\
\hline $\begin{array}{l}\text { Whether to go to the hospital/health center/clinic for cough, } \\
\text { expectoration and shortness of breath }\end{array}$ & & & & & 0.023 \\
\hline Yes & 37 & 88 & 37 & 10 & \\
\hline No & 97 & 182 & 45 & 8 & \\
\hline Have you had a pulmonary function test & & & & & 0.226 \\
\hline Yes & 1 & 5 & 4 & 0 & \\
\hline No & 133 & 265 & 78 & 18 & \\
\hline Understand/know what chronic obstructive pulmonary disease is & & & & & 0.009 \\
\hline Yes & I & 16 & 7 & 2 & \\
\hline No & 133 & 254 & 75 & 16 & \\
\hline
\end{tabular}


Table 7 Clinical Manifestations of COPD

\begin{tabular}{|c|c|c|c|c|c|}
\hline Clinical Symptoms & $\begin{array}{l}\text { COPD } \\
(n=504)\end{array}$ & $\begin{array}{l}\text { Non-COPD } \\
(n=2459)\end{array}$ & p-value & OR (95\% Cl) & $\begin{array}{c}\text { Total } \\
(n=2963)\end{array}$ \\
\hline Cough (n, \%) & & & $<0.001$ & $3.17(2.61,3.86)$ & \\
\hline Yes & 279 (55\%) & 691 (28\%) & & & 970 (33\%) \\
\hline No & 225 (45\%) & I 768 (72\%) & & & 1993 (67\%) \\
\hline Dyspnea (n, \%) & & & $<0.001$ & $3.09(2.53,3.77)$ & \\
\hline Yes & $231(46 \%)$ & 529 (22\%) & & & $760(26 \%)$ \\
\hline No & $273(54 \%)$ & 1930 (78\%) & & & 2203 (74\%) \\
\hline Bilateral edema (\%) & & & $<0.001$ & $6.8 \mathrm{I}(4.46,10.47)$ & \\
\hline Yes & $51(10 \%)$ & $40(2 \%)$ & & & 91 (3\%) \\
\hline No & 453 (90\%) & 2419 (98\%) & & & $2872(97 \%)$ \\
\hline Chest pain & & & 0.07 & $1.46(0.97,2.12)$ & \\
\hline Yes & $35(7 \%)$ & 120 (5\%) & & & 155 (5\%) \\
\hline No & $469(93 \%)$ & 2339 (95\%) & & & 2808 (95\%) \\
\hline $\begin{array}{l}\text { Whether due to seasonal changes in the weather cool cough, } \\
\text { cough sputum, shortness of breath }(n, \%)\end{array}$ & & & $<0.001$ & $2.90(2.37,3.56)$ & \\
\hline Yes & $207(41 \%)$ & $476(19 \%)$ & & & $683(23 \%)$ \\
\hline No & 297 (59\%) & 1983 (81\%) & & & 2280 (77\%) \\
\hline Whether to smell and irritant odor cough, asthma symptoms (n, \%) & & & $<0.001$ & $2.09(1.68,2.59)$ & \\
\hline Yes & $158(3 \mid \%)$ & $441(18 \%)$ & & & $599(20 \%)$ \\
\hline No & $346(69 \%)$ & $2018(82 \%)$ & & & $2364(80 \%)$ \\
\hline $\begin{array}{l}\text { Have you ever coughed up sputum for } 2 \text { consecutive years, } 3 \\
\text { months per year or more }(n, \%)\end{array}$ & & & $<0.001$ & $8.01(6.47,9.91)$ & \\
\hline Yes & $263(52 \%)$ & $295(12 \%)$ & & & $558(19 \%)$ \\
\hline No & $241(48 \%)$ & $2164(88 \%)$ & & & $2405(81 \%)$ \\
\hline Whether to cough up sticky phlegm (n, \%) & & & $<0.001$ & $3.49(2.76,4.42)$ & \\
\hline Yes & $|4|(28 \%)$ & $246(10 \%)$ & & & $387(13 \%)$ \\
\hline No & $363(72 \%)$ & $2213(90 \%)$ & & & $2576(87 \%)$ \\
\hline $\begin{array}{l}\text { Recent days whether there is a cold, tracheitis, pneumonia and } \\
\text { other respiratory diseases ( } n, \%)\end{array}$ & & & $<0.001$ & $3.73(2.54,5.44)$ & \\
\hline Yes & 49 (10\%) & 69 (3\%) & & & II8 (4\%) \\
\hline No & 455 (90\%) & 2390 (97\%) & & & 2845 (96\%) \\
\hline
\end{tabular}

in China was as high as $8.2 \%$. In the 2016 annual meeting of the European Respiratory Society (ERS), Wang Chen et al reported that the prevalence of COPD in China was $14.1 \%$ for people over 40 years old, and $8 \%$ for people over 20 years old. ${ }^{1,6}$ It is noteworthy that although the overall prevalence of COPD in urban areas is higher than that in rural areas, the prevalence of COPD in rural areas increases more rapidly than that in urban areas. The prevalence of COPD in urban areas increased from 13.2\% (120 million) in 1990 to $13.6 \%$ (230 million) in 2010, and that in rural areas increased from $8.8 \%$ (106 million) to $9.7 \%$ (153 million). ${ }^{7}$
In this study, the prevalence of COPD in the Uyghur people in the Kashi region was $17.01 \%$, which was significantly higher than other regions of China. This study revealed significant differences in prevalence in different regions. Among them, based on the existing survey data, it is speculated that Shache county has the highest crude prevalence, but the sample size needs to be further expanded. Logistic regression analysis of this study found that age, gender, physical exercise, kitchen ventilation, cooking, smoking, intake of fruits and vegetables, BMI, waist circumference, and hip circumference were uniformly significantly associated with COPD, the high 
age, smoking, lower BMI, high waist circumference, systolic blood pressure, high cooking fat methods, and fried barbecue may be a risk factor for COPD, whereas intake of fruits and vegetables may be protective factors for COPD. It is considered that malnutrition in this population may lead to a decrease in the tolerance of respiratory muscle function, which makes it prone to respiratory muscle fatigue and aggravates ventilation dysfunction, and promotes the formation and occurrence of COPD. In addition, we found that age is also a risk factor for COPD, with the increase of age, the prevalence of COPD is also on the rise, it is considered that with the increase of age, the physical function of the human lung was aging and the prevalence of COPD is also increasing. This study shows that fried cooking methods and barbecue may be risk factors for COPD, this is related to the living habits of the Uyghur population in Kashi because they like to eat deep fried foods and barbecued meat. It may be due to harmful substances, such as formaldehyde, benzene and acrolein, that will be released from the food when fire roasting and frying, which will increase the susceptibility of the lung to pathogens, aggravate the respiratory system symptoms and reduce the lung function, and increase the risk of COPD. Therefore, when cooking, we should reduce the barbecueing and frying of food and cook food in healthier ways. When cooking, we should wear protective masks and reduce the inhalation of harmful substances. This study also found that the intake of fruits and vegetables is a protective factor of COPD. WHO statistics show that in 2017 there were 3.9 million deaths worldwide related to the inadequate intake of fruits and vegetables. Fresh fruits and vegetables are important sources of vitamins, minerals, dietary fiber and phytochemicals. Increasing the intake of fruits and vegetables can reduce cardiovascular disease. This study also concluded that the intake of fruits and vegetables can lower the risk of COPD.

Having, for 2 years in a row, and for each year more than 3 months or cumulatively for 3 months, coughing and expectoration, coughing up phlegm, and recently having a cold, bronchitis, pneumonia, or other respiratory disease factors, are associated with a significant risk of COPD People who often appear with these symptoms are more likely to developed to COPD, and thus should go to hospital as early as possible, as early treatment will improve the cure rate of the disease. This study reflects that many patients have only a mild awareness of COPD, the lack of awareness and the lack of early preventive treatment, misses the chance of early diagnosis and treatment, causing COPD with poor prognosis and high case fatality. Therefore, medical workers should strengthen the awareness of COPD in the rural population and pay more attention to early detection of symptoms by which patients can get early treatment as soon as possible.

\section{Conclusions}

Our study found that the prevalence of COPD among the Uyghur population in the Kashi region was higher than other regions in China. High age, smoking, low BMI, high waist circumference, high systolic blood pressure, and cooking methods such as stir-fried and deep-fried barbecue may be risk factors for COPD, whereas vegetable and fruit intake may be a protective factor for COPD.

\section{Disclosure}

The authors report no conflicts of interest in this work.

\section{References}

1. Zhu B, Wang Y, Ming J, et al. Disease burden of COPD in China: a systematic review. Int J Chron Obstruct Pulmon Dis. 2018; 13:1353-1364. doi:10.2147/COPD.S161555

2. Regional COPD working group. COPD prevalence in 12 Asia-Pacific countries and region: projections based on the COPD prevalence estimation mode. Respirology. 2003;8(2):192-198. doi:10.1046/ j.1440-1843.2003.00460.x

3. Vogelmeier CF, Criner GJ, Martinez FJ, et al. Global strategy for the diagnosis, management, and prevention of chronic obstructive lung disease 2017 report. Am J Respir Crit Care Med. 2017;195(5):5 57-582. doi:10.1164/rccm.201701-0218PP

4. Adeloye D, Chua S, Lee C, et al. Global and regional estimates of COPD prevalence: systematic review and meta-analysis. $J$ Glob Health. 2015;5(2):020415. doi:10.7189/jogh.05.020415

5. Diaz-Guzman E, Mannino DM. Epidemiology and prevalence of chronic obstructive pulmonary disease. Clin Chest Med. 2014;35(1): 7-16. doi:10.1016/j.ccm.2013.10.002

6. Wang C, Jiangying X, Yang L. Prevalence and risk factors of chronic obstructive pulmonary disease in China (the China pulmonary health $[\mathrm{CPH}]$ study): a national cross-sectional study. Lancet. 2018;391 (10131):1706-1717. doi:10.1016/S0140-6736(18)30841-9

7. Lindberg A, A C J, Rönmark E, et al. Prevalence of chronic obstructive pulmonary disease according to BTS, ERS, GOLD and ATS criteria in relation to doctor's diagnosis, symptoms, age, gender, and smoking habits. Respiration. 2005;72(5):471-479. doi:10.1159/0000 87670 


\section{Publish your work in this journal}

The International Journal of COPD is an international, peer-reviewed journal of therapeutics and pharmacology focusing on concise rapid reporting of clinical studies and reviews in COPD. Special focus is given to the pathophysiological processes underlying the disease, intervention programs, patient focused education, and self management protocols. This journal is indexed on PubMed Central, MedLine and CAS. The manuscript management system is completely online and includes a very quick and fair peer-review system, which is all easy to use. Visit http://www.dovepress.com/testimonials.php to read real quotes from published authors. 